\title{
PERSPECTIVES ON THE RISK IN MILITARY CAPABILITIES MANAGEMENT
}

\author{
Dumitru IANCU, Anca DINICU, Gabriel MĂNESCU \\ "Nicolae Bălcescu" Land Forces Academy, Sibiu, Romania \\ dorin_dan@yahoo.com
}

\begin{abstract}
The need for efficient management of defense-related resources has become a primary objective for every nation, regardless of whether it belongs to an alliance or not. Current societal challenges generate a series of redrafts of how these resources are managed. Only a quantitative approach to defense resources is no longer a solution, but an integrated medium and long-term approach is an appropriate solution to the new security environment. The risk, as a component of military capabilities management, should be carefully analyzed, localized and treated in order not to jeopardize the effectiveness of the use of defense resources.
\end{abstract}

Keywords: capability, risk, management, military

\section{Introduction}

The risk is present in all activities, individual or collective, and primarily affects human resources because they have the cognitive ability to understand it. Every day we meet risks, whether we realize it or not. When we talk, run, work, play, we meet the risk. It is obvious that the risk is found in all activities and actions carried out in the military field, but we believe that identifying, analyzing and designing its management within the management of military capabilities process can substantially reduce its occurrence.

\section{From Military Capacities Management to Military Capabilities Management}

Contemporary challenges in the management of military organizations have led to a rethinking of the ways in which the resources needed to meet specific objectives are analyzed, determined and used. It is noted that the general trend towards the efforts of nations to support military activities is decreasing as the general requirements of societies have shifted to the detriment of the military field: major investments in the health of citizens, measures to stop the aging of the population, actions to slow the global warming phenomenon, etc. But this fact did not necessarily lead to a diminution in the level and volume of the military organizations' missions, as it can be said that their spectrum has even diversified given the perspectives of analysis and the dynamics of the risks, threats and vulnerabilities that underlie the strategies elaborated in this domain. (Figure 1, example the last two National Defense Strategies in Romania) 


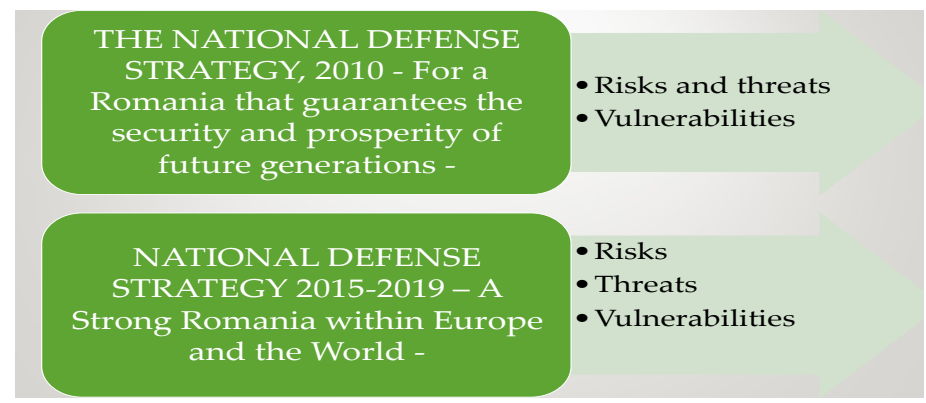

Figure 1: Comparison of the ways to approach some of the components of the strategies

Maybe at first view, we might say that they are similar approaches, but without nuancing now the conceptual differences of those three elements, the ways of response are totally different if they are treated individually or grouped on certain criteria, with direct consequences on the need for related resources.

These two premises corroborated (economic and doctrinal) have led to the rethinking of management in the field of defense resources (starting from the alliance level), going from military capacities management to military capabilities management. Since it is not relevant to the success of military action if defense capabilities (forces, armaments, information, etc.) exist in quantity and quality, but not where they are needed. The dynamics of military action requires, first of all, high mobility of forces in the spacetime binomial, which implies adequate logistical support, becoming a fundamental objective of the alliance: "NATO's modern defence posture is based on an effective combination of two key pillars: cuttingedge weapons systems and platforms, and forces trained to work together seamlessly. As such, investing in the right capabilities is an essential part of investing in defence. NATO plays an important role in assessing what capabilities the Alliance needs; setting goals for national or collective development of capabilities; and facilitating national, multinational and collective capability development and innovation"[1].

Military capacities management mainly focused on identifying/calculating resource requirements according to the level and magnitude of the objectives of military structures within a given time horizon, without interfering with them; military capability management is aimed not only at determining the need for resources over a much wider time horizon, but also how they can simultaneously/intermittently contribute to achieving more goals. The concrete forms that the interdependence between the components of the military capabilities (Figure 2) can take will be, in essence, the prerequisites for the expression of the level of efficiency of military mission accomplishment.

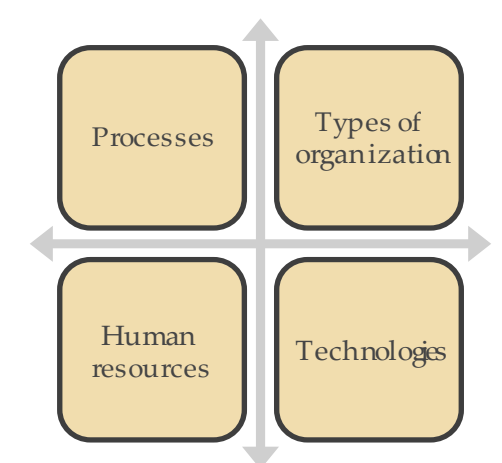

Figure 2: Components of military capabilities in NATO 
Developed in the technical field, we consider the Capability Maturity Model Integration (CMMI) to be a solution through which military capabilities management achieves a high degree of efficiency, even if we have a high complexity of both entry and exit elements.

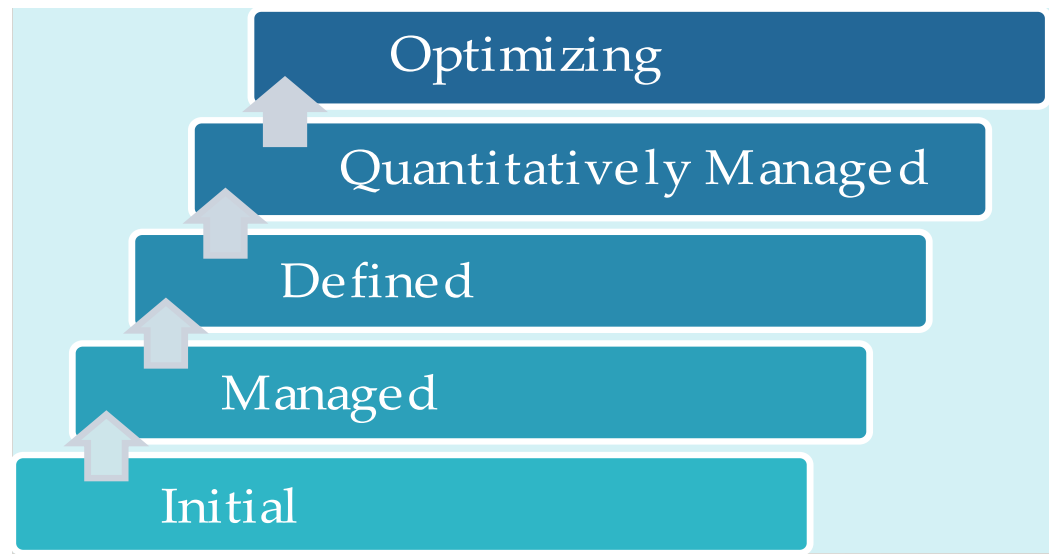

Figure3: The Capability Maturity Model Integration

The Capability Maturity Model Integration Levels are:

a) "-Initial - Processes are usually ad hoc and chaotic. Unstable environment. Depends on competence and heroics. Tendency to over commit, abandonment of processes and inability to repeat successes. Process area: None (ad hoc);

b) - Managed - Requirements are managed and processes are planned, performed, measured, and controlled.

Seven process areas: Requirements Management, Project Monitoring and Control, Project Planning, Supplier Agreement Management, Configuration Management, Measurement and Analysis, Process and Product Quality Assurance;

c) - Defined - Processes are well characterized and understood and are described in standards, procedures, tools, and methods. Processes are managed more proactively.

Process area: Product Integration, Requirements Development, Technical Solution, Validation, Verification, Organizational Process Definition, Organizational Process Focus, Organizational Training, Integrated Project Management, (Project) Risk Management, Decision Analysis and Resolution; d) - Quantitatively Managed Predicable process performance. Processes are controlled and measured.

Process area: Organization Process Performance, Quantitative Project Management;

e) - Optimizing - Continual process improvement. Addresses common causes of process variation.

Process Area: Organization Innovation and Deployment, Causal Analysis and Resolution" [2].

This model is run by the CMMI Institute, a branch of the ISACA (Information Systems Audit and Control Association), and designed by Carnegie Mellon University (CMU).

\section{The place and role of risk management in achieving military capabilities}

Although in general terms risk is perceived as a negative value in relation to the human activity, it should be approached at the organizational level as a positive element, because:

"- we take risks not to avoid dangers, but to get benefits and to win;

- assuming controlled and known risks, we live the beautiful and essential part of life every day;

- the higher the risk, the higher the reward will be; 
- there is no risk without progress" [3].

Military capabilities management is a process where risk is more present and more powerful than other processes specific to the military organization.

Firstly, the military capability is related to the medium to long-term future, which can be predicted when the factors under consideration do not fundamentally change - for example: the life cycle of a technological product can be predicted depending on how it is used, quality of maintenance, etc. but there is a risk that the effects of its use will no longer reach the accepted efficiency level in a few years.

Secondly, military capabilities must be built and used to meet a set of objectives set against the economic developments of the nations, but on the dynamics of the last thirty years the predictability of these developments has been quite difficult to find in real events.

And a third argument (without claiming that we have exhausted their list), military capabilities depend in an overwhelming way on the value and quality of the human resource, both at the decision-making level and at the execution level. For example: it is possible to predict the evolution of the factor demographically combined with the state of education, but the risk of losing the highly qualified human resource in the military field in favor of other areas of society is quite pregnant.

Undoubtedly, the risk management in the military capabilities management must be in a central place of the vision of military managers. Regardless of the stage where a particular military capability is found, by reference to the CMMI model, the associated risks must be identified, analyzed, calculated and managed by:

- building a scheme of roles and responsibilities in relation to risk management;

- establishing a set of clear procedures to be applied in the conduct of the risk management process;

- detailing exactly, in space and time (programming), the actions carried out in the framework of risk management processes;

- allocating financial resources distinctly to risk management as part of the military capabilities management.

From the point of view of the content of the risk management process in achieving military capabilities, it includes the same steps as the military decision-making process:"risk planning; identification and definition of risk, risk analysis; establishing risk management paths; risk monitoring and control" [4].

\section{Conclusions}

Although from a managerial point of view, the issue of risk is complicated and a big time-consuming affair, we believe that it should express, at the design and implementation part, the predictability of the level of ambition in the field of military capabilities management.

\section{References}

[1] https://www.nato.int/cps/en/natohq/topics_49137.htm.

[2] https://www.sciencedirect.com/topics/computer-science/capability-maturity-modelintegration.

[3] Iulian Vișoiu and CostacheRusu, Implementarea managementului riscului la nivel organizational (Ghid aplicativ), București, Editura Economică, 2010, p 22.

[4] Dumitru Iancu, Dorel Badea, Particularities relating to the risk management into the military decision-making process, International Conference KNOWLEDGE-BASED ORGANIZATION, Vol. XXIV, No 1, 2018, p. 322. 